Erratum

\title{
Control of spontaneous emission spectra via an external coherent magnetic field in a cycle-configuration atomic medium
}

J.H. Li

Department of Physics, Huazhong University of Science and Technology, Wuhan 430074, P.R. China

Received 4 May 2007

Published online 29 June 2007 - C EDP Sciences, Società Italiana di Fisica, Springer-Verlag 2007

Eur. Phys. J. D 42, 467-473 (2007)

The second affiliation "Institute of Advanced Energy, Kyoto University, Gokasho, Uji, Kyoto 611-0011, Japan" should be withdrawn from this paper.

\footnotetext{
a e-mail: huajia_li@163.com
} 